\title{
Void Shrinkage and Void Lattice Formation in Neutron-irradiated Molybdenum
}

\section{J. Bentley}

\author{
Microscopy and Microanalytical Sciences, PO Box 7103, Oak Ridge, TN 37831-7103, USA
}

It has been more than 40 years since the void lattice was first observed by TEM in Mo irradiated to a high dose at elevated temperatures with $\mathrm{N}$ ions [1] or fast (breeder) reactor neutrons [2]. Similar observations of void and bubble lattices were made in other bcc refractory metals and, subsequently, in fcc metals such as Ni and with less perfect void alignment also in hexagonal metals (reviewed in [3]). Different theories and models were proposed for void lattice formation and stability, notably ones based on elastic interactions between voids [e.g. 4]. Interestingly, a model based on one-dimensional (1D) interstitial migration [5] was not well received at first. However, following decades of simulation research, 1D migration of interstitials and clusters of a few interstitials is now generally accepted to occur, and indeed recent modeling studies show it is responsible for void lattice formation [e.g. 6]. Void lattices are frequently quite imperfect but are always aligned parallel to their host crystallographic lattice, have narrow cavity size distributions and void lattice parameters of typically 10-100 nm [e.g. 7].

Although void lattices have been observed only after high-dose irradiations, some insight into the early stages of void lattice formation can be gained from low-dose, high-temperature neutron irradiation of Mo. High-purity single-crystal Mo (4PZR), polycrystalline Mo (AR) and TZM alloy (Mo-0.5\%Ti$0.1 \% \mathrm{Zr}$ ) were irradiated as $3-\mathrm{mm}$ disks in fully instrumented rigs at $330,475,575,650,750$ and $850^{\circ} \mathrm{C}$ to neutron fluences $(>1 \mathrm{MeV})$ of $\sim 1$ and $\sim 3 \times 10^{24} \mathrm{~m}^{-2}$ ( $\sim 0.05$ and $\sim 0.15 \mathrm{dpa}$, respectively) in the PLUTO research reactor at AERE Harwell in 1972 [8]. Dimpled disks were electro-polished at 8V in cooled, static $25 \% \mathrm{H}_{2} \mathrm{SO}_{4}-75 \% \mathrm{CH}_{3} \mathrm{OH}$ and characterized by TEM at $100 \mathrm{kV}$ with a Philips EM300 and at 600 $\mathrm{kV}$ with an AEI EM7 [8]. Figure 1 shows micrographs of voids in 4PZR Mo irradiated at 575, 650, 750 and $850^{\circ} \mathrm{C}$ to $\sim 1$ and $\sim 3 \times 10^{24} \mathrm{~m}^{-2}$, and fig. 2 shows the measured void size distributions. An important observation for irradiation at $575^{\circ} \mathrm{C}$ and higher is that although void concentration (number density) increases significantly with increased fluence (dose), the largest voids have shrunk under continued irradiation. This is not just a sampling problem; for specimens irradiated to $\sim 3 \times 10^{24} \mathrm{~m}^{-2}$ at 750 and $850^{\circ} \mathrm{C}$, areas several orders of magnitude larger than used for measuring size distributions were surveyed but no large voids were observed. The AR Mo exhibited similar behavior but for TZM completely different phenomena involving impurity-stabilized vacancy loops were observed [8]. It must be emphasized that void shrinkage under continued, nominally constant irradiation conditions is inconsistent with conventional models of the development of damage microstructures. Although no void alignment was observed, the shrinkage was speculated as being associated with void lattice formation [8]. That is now more clearly the case. With continued void nucleation, aided by transmutation-produced gases (especially $\mathrm{He}$ and $\mathrm{H}$ ), as the void spacing approaches the mean free path length of 1D interstitial motion, void nuclei located along the close-packed $<111>$ near an existing void will experience a slightly lower interstitial flux, because of 1D interstitial cluster migration along $<111>$ and the shadowing effect from the existing void, and thus experience a slightly greater growth rate. The largest voids will obviously create the largest shadows. However, the shadowing is mutual and as the void concentration increases the larger voids will experience less protection from shadowing than neighboring smaller voids and thus experience relatively greater interstitial annihilation. With an appropriate combination of additional void nucleation and swelling rates it is thus possible that the largest voids will shrink, with the "lost" vacancies effectively being redistributed to smaller voids on the nascent void lattice. The swelling rate is still determined by the dislocation bias, the net flux of interstitials to dislocations (mostly coarse networks in these specimens where voids are the dominant sink [8]). Ultimately, as the void lattice forms and becomes more perfect, the mutual void shadowing dominates and leads to a very narrow distribution of void sizes. Although continued void nucleation and broad void size distributions have not yet been incorporated into modeling studies, it could be instructive to do so in order to confirm and find the limiting conditions for void shrinkage. Finally, it is perhaps interesting to realize that had the PLUTO irradiations continued from 1972, they would just now be reaching the fluences $\left(\sim 5 \times 10^{26} \mathrm{~m}^{-2}\right)$ typical of the fast-reactor irradiations that produce clearly defined void lattices [9]. 
1. J H Evans, Nature 229 (1971) 403-404.

2. F W Wiffen, in Radiation-induced Voids in Metals (eds J W Corbett \& L C Lanniello) USAEC-CONF-71061, 386-396 (Albany, New York, 1972).

3. W Jager and H Trinkaus, J Nucl Mater 205 (1993) 394-410.

4. V K Tewary and R Bullough, J Phys F 2L (1972) 69-72.

5. A J E Foreman, AERE Rep R-7135 (1972).

6. A V Barashev and S I Golubov, Philos Mag 90 (2010) 1787-97.

7. J Bentley and F W Wiffen, in The Technology of Controlled Nuclear Fusion, CONF-760935-P1 (1977) 208-18.

8. J Bentley, PhD Thesis, University of Birmingham, England, 1974. See also J Bentley, B L Eyre and M H Loretto, Fundamental Aspects of Radiation Damage in Metals (eds M T Robinson \& F W Young Jr) CONF751006-P2 (1976) 925-931 and J Bentley, B L Eyre and M H Loretto, Rad Effects \& Tritium Technol for Fusion Reactors (eds J S Watson \& F W Wiffen) CONF-750989-Vol 1 (1976) 297-311.

9. The author greatly appreciates the recent help of Dr. Neal D. Evans and the long-ago help and advice of Dr. Mike H Loretto, Dr. Brian L Eyre, Mr. A F Bartlett and Mr. E A Terry. The original TEM research was performed at the University of Birmingham, England with financial support from UKAEA, AERE Harwell.

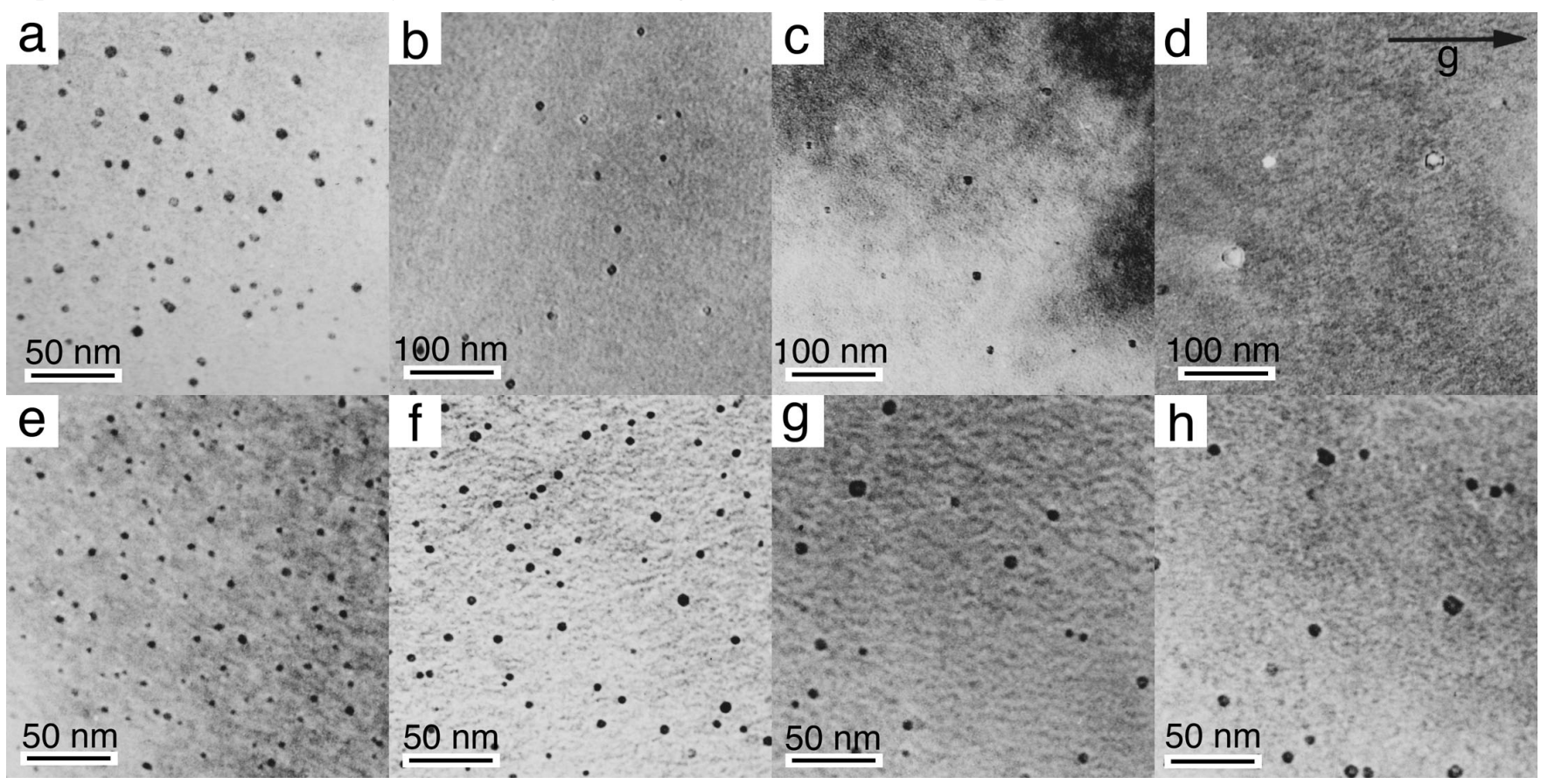

Figure 1. 100-kV TEM images showing voids in 4PZR Mo neutron irradiated to (a-d) $\sim 1 \times 10^{24} \mathrm{~m}^{-2}(\mathrm{e}-\mathrm{h}) \sim 3 \mathrm{x}$ $10^{24} \mathrm{~m}^{-2}$ at $(\mathrm{a}, \mathrm{e}) 575^{\circ} \mathrm{C}$, (b,f) $650^{\circ} \mathrm{C},(\mathrm{c}, \mathrm{g}) 750^{\circ} \mathrm{C}$ and (d,h) $850^{\circ} \mathrm{C}$. For all micrographs beam direction $\mathbf{Z}=$ [155], diffraction vector $\mathbf{g}=[0-33]$, deviation parameter $\mathrm{s}_{\mathrm{g}}>0$, specimen thickness $\mathrm{t} \sim 3.5 \xi_{110} \sim 70 \mathrm{~nm}$ (where $\xi_{\mathrm{g}}$ is the extinction distance) and objective lens overfocus $\sim 1 \mu \mathrm{m}$ such that voids are in dark contrast with a bright Fresnel fringe outside the void.

Figure 2. Void size distributions in neutron irradiated 4PZR Mo. The legend format (e.g. 850/1/0.03) is irradiation temperature ${ }^{\circ} \mathrm{C} /$ fluence $\mathrm{x} 10^{24} \mathrm{~m}^{-2}$ / swelling \%. Note the estimated error of swelling values is $\pm 50 \%$. For clarity, data for irradiations at 330 and $475^{\circ} \mathrm{C}$ are inset with an expanded abscissa.

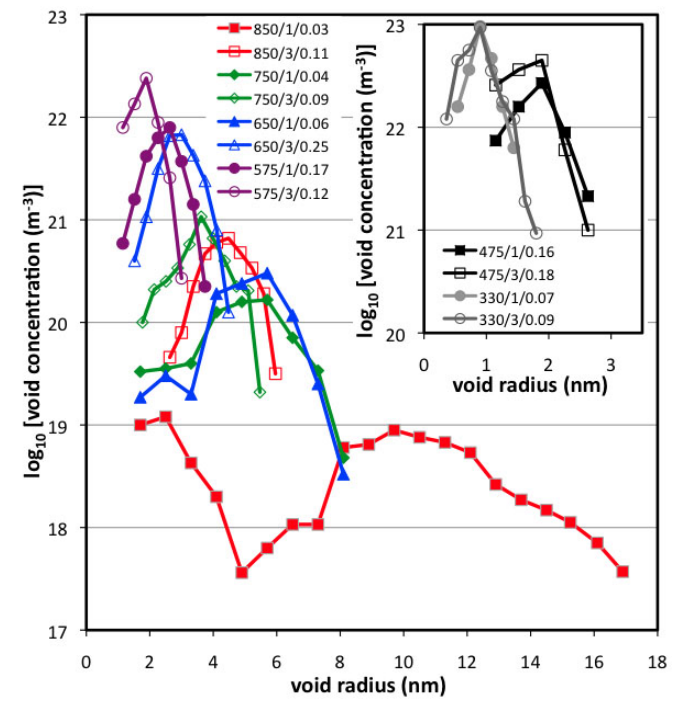

